\title{
Resultados parciais e expectativas frustradas: os Cunha Mattos sob as reformas de Lippe
}

\author{
Neuma Brilhante Rodrigues* \\ Universidade de Brasília \\ Brasília - Distrito Federal
}

Proponho analisar alguns desdobramentos das ações de Conde de Lippe em Portugal (1762-1777) nas trajetórias de três militares da família Cunha Mattos. O texto busca mostrar como as reformas militares adotadas pelo Conde de Oeiras foram credenciais para o então brigadeiro do Exército brasileiro na década de 1820, José da Cunha Mattos, retratar-se em suas Memórias como participante de certa tradição militar inaugurada pelo comandante prussiano. As menções das carreiras de seu avô e de seu pai presentes em suas Memórias permitem vislumbrar alguns desdobramentos de tais reformas na vida do baixo oficialato eo modocomo foram ressignificadas no contexto do Brasilindependente.

Conde de Lippe; Reforma militar; Cunha Mattos.

* Graduada, Mestre e Doutora em História pela Universidade de Brasília (UnB) e Professora Adjunta do Departamento de História da Universidade de Brasília. E-mail: neumabr@uol.com.br. 


\section{Partial results and unfulfilled expectations: the Cunha Mattos under renovation Lippe}

Neuma Brilhante Rodrigues

Universidade de Brasília Brasília - Distrito Federal

I propose to examine some consequences of the actions of Count Lippe in the trajectories of three militaries of Cunha Mattos's family. The text aims to show how, despite the undeniable limitations of those military reforms adopted under the tutelage of Count Oeiras, they remained credentials to the then Brigadier Army Brazilian Raimundo José da Cunha Mattos, in the ides of the 1820 's, portraying himself in his memoirs as an heir in a military tradition inaugurated by the famous Prussian commander. The endorsement of the careers of his grandfather and father allow us to understand theimpact of such reforms in thelives of the low officialate and how they have been re-signified in the context of independent Brazil.

Count Lippe ; Military reform; Cunha Mattos 
Entre os anos de 1762 e 1777, o conde Wilhelm von Schaumburg-Lippe, o célebre conde de Lippe, foi o comandante geral das tropas portuguesas e o principal agente de uma reforma militar patrocinada pelo Marquês de Pombal.Tal como as demais iniciativas de reformas empreendidas pelotodo poderoso ministro de $\mathrm{d}$. José, o alcance das novidades na área militar tem sido questionado pela historiografia especializada.

Fernando Dores Costa, por exemplo, em consistentes trabalhos sobre a presença do Conde em Portugal, considera que as reformas sofreram com a resistência da sociedade ao processo de militarização de acordo com o modelo prussiano de exército, pautado em dura disciplina que visava moldaros corpos e os comportamentos dos soldados, a fim de torná-los militarmente funcionais. Diante disto, a efetividade das reformas de Lippe teria sido pontual e significativa apenas durante o comando do Conde. ${ }^{1}$

Mesmo assumindo que os resultados das reformas ilustradas em Portugal tenham sidobastanteparciais, encontramos referênciasaelasnasfalas de diferentessujeitoshistóricos, pelomenosatéasprimeirasdécadasdooitocentos tanto em Portugal quanto no Brasil. No caso das reformas militares, seu legado permaneceu no aparato legal, na constituição da Justiça Militar enas academias responsáveis pela formação dos oficiais.

O presente artigo se propõe a discutir desdobramentos da ação de Lippe em Portugal a partir das trajetórias de três membros da família Cunha Mattos. É preciso observar que aqui não se consideram as experiências dos Cunha Mattos como casos típicos ou a prova do sucesso das reformas. Pretende-seindagaracercadoexercício daliberdadedeescolhadossujeitoshis-

COSTA, Fernando Dores. "O bom uso das paixões: caminhos militares na mudança do modo de governar." In: Análise Social, Lisboa, vol. XXXIII (149), 1998 (5), p. 983. Já em 1806, Gomes Freire de Andrade apresentou, na introdução de seu plano de reforma militar, severa crítica à tendência da aplicação de organizações e táticas militares estrangeiras em Portugal sem considerar a adequação das mesmas "ao seu génio e País", desobedecendo ao princípio de que a organização dos exércitos deveria estar de acordo com a "Constituição Civil deste [qu]e encerra a base de qualquer Constituição Militar." ANDRADE, Gomes Freire de. Ensaio sobre o méthodo de organizar emPortugaloExércitorelativoàpopulação,agriculturaedefesadopaís.NovaOfficinadeJoãoRodrigues Neves: Lisboa, 1806, p. V. 
tóricos em meio aos "interstícios inerentes aos sistemas gerais de normas"2, o que resulta de sua capacidade de compreensão e manipulação do sistema normativo ${ }^{3}$.

No caso, busca-se compreender melhor as estratégias escolhidas por aqueles personagens em meio ao contexto das mudanças militares que se deram em Portugal entre finais do setecentos e primeiras décadas do oitocentos. Esse contexto, por sua vez, é explorado em sua complexidade, com as expectativas, dúvidas, sucessos efracassos dos propositores das reformas.

Em busca de iluminar tais questões, foram utilizadas diferentes fontes comocartaspatentes,certidões defé-de-ofícioepeçasdorepertórionormativo do período analisado. Essas fontes foram pensadas em diálogo com o manuscritoMemóriaspolíticas, militaresebiográficas, deRaimundoJosédaCunha Mattos ${ }^{4}$. Esse texto refere-se ao processo de formação do autor, fortemente influenciado, segundo ele, pelas trajetórias de seu pai e de seu avô, por seus estudos na Casa Pia de Lisboa e na Escola Regimental do Algarve e pela experiência nos campos de guerra, como soldado da Divisão Auxiliadora à Coroa da Espanha, na campanha do Roussilhão e da Catalunha, contra a França, entre 1793 e 1795. Esse conflito, aliás, é o principal objeto do manuscrito. A representação elaborada por Raimundo José nos permite vislumbrar aspectos do cotidiano das tropas sobelogo após a ação do conde prussiano, da recepção das novidades e reações diante de suas possibilidadese incertezas.

O uso de textos de caráter autobiográfico como fonte exige por parte do historiador a consciência de que "se alguém se põe a escrever uma autobiografia, é porque tem em mente fixar um sentido em sua vida e dela operar uma síntese." Tal busca de significação e síntese orienta a seleção dos"acontecimentos ou reflexões [que] devem ser omitidos equais (ecomo)

2 LEVI, Giovanni. Usos da biografia. In: FERREIRA, Marieta de Moraes; AMADO, Janaína. Usos e abusos da história oral. 8.ed. Rio de Janeiro: Ed. FGV, 2006, p. 179. Sobre o debate acerca do lugar da biografia na historiografia, ver: SOUZA, Adriana Barreto de. Pesquisa, escolha biográfica e escrita da história: biografando o duque de Caxias. História da Historiografia, Ouro Preto, n. 9, , ago. 2012, p. 106-128..

3 SOUZA, Adriana Barreto. Op. Cit., p. 124.

4 MATTOS, RaimundoJosédaCunha.Memórias políticas, militaresebiográficas. Biblioteca Nacional do Rio de Janeiro (BNRJ), Seção de Manuscritos, 10,2,016. A partir daqui, resumidamente, Memórias. 
devem ser narrados". ${ }^{5} \mathrm{O}$ autor desse tipo de texto atua como um editor, no sentido americano, de sua vida: não cria, mas ordena e melhora um texto já existente.

Entre as críticas ao uso desse tipo de texto está a noção de que a autobiografia“lançamais luzsobreo estado deespírito doautorquandoescreveu suas lembranças do que no momento em que os eventos realmente ocorreram". 6 Tal aspecto, ao invés de ser visto aqui como um impedimento, é tido comouma daschaves deinterpretação dafonte, umavezqueRaimundoJosé parece ter tido bastante clareza disso, o que explica a definição de seu texto como biografia e memórias, na junção do que chamou de "duas classes de história"7. A primeira, voltada para a narração de grandes acontecimentos testemunhados pelos autores, a segunda, por sua vez, para a formação das personalidades, no caso, ao próprio autor. ${ }^{8}$

No ato de escrever sobre si, Raimundo José da Cunha Mattos esforçouse em se retratar como um homem herdeiro das iniciativas de modernização empreendidas pela Coroa portuguesa setecentista e que experimentou significativa ascensão profissional e social decorrente de sua formação e de seus méritos pessoais. Considera-se que, no momento em que escrevia, nos primeiros anos do Brasil independente, Cunha Mattos construiu uma narrativa de si útil para suas pretensões de ascensão social bem como políticas, na articulação entre o social e o pessoal.

Raimundo José, apesar de obviamente se identificar com o espírito das reformas setecentistas e se entender como herdeiro delas, não se furtou a criticar suas limitações. O texto contém severas observações quanto às con-

5 ALBERTI, Verena. "Literatura e autobiografia." In: Estudos Históricos, Rio de Janeiro, vol. 4, n. 7, 1991, p. 77.

6 LAQUEUR, Walter. Thursday's Child Has Far to Go: A Memoir of the Journeying Years. New York: Scribner, 1993, p. 401.

7 MATTOS, Raimundo José da Cunha. Memórias... Op. Cit.

8 Deve-se observar que autobiografia é um neologismo a se consolidar ao longo do oitocentos "Le mot nouveau n'indique pas l'emergence d'un nouveau genre d'ecriture; dans son pédantisme, il atteste plutot la formation d'un vocabulaire technique de la critique au début du XIXe siècle." GUSDORF, Georges. “De l'autobiographie initiatique à l'autobiographie genre littéraire." In: Revue d'Histoire Littéraire de la France, Paris, 75e Année, n. 6, Nov-Dec, 1975, p. 963. 
dições do serviço das armas, tanto à época de seu pai, em Portugal, como no Brasil naqueles anos iniciais do Império, e retratam claramente sua impressão da ocorrência de certa decadência da organização das tropas decorrente do afastamento do modelo por ele conhecido na juventude.

O presente artigo, portanto, articula a narrativa de Raimundo José com outras fontes e busca pensar como as vidas de Francisco Xavier, Alexandre Manoel e Raimundo José, três gerações de uma mesma família, foram impactadas pelas ações empreendidas pelo conde de Lippe, tendo por fio condutor as Memórias. O primeiro chegou a servir na Guerra Fantástica, como ficou conhecida o capítulo da Guerra dos Sete anos ocorrido na Península Ibérica, na qual o conde era o comandante em chefe das tropas portuguesas. Alexandre Manoel assentou praça imediatamente após a implantação dos novos regulamentos e serviu sob as ordens diretas de alguns dos colaboradores mais próximos do conde. E Raimundo José se sentia um herdeiro das reformas implantadas pelo conde nos 15 anos em que ele e oficiais de sua confiança comandaram o exército português.

Nessesentido, devemosconsiderarque, seasmedidastomadasporConde de Lippe e seus oficiais não foram tão efetivas, foram significativas o suficiente para valer o esforço do então brigadeiro do Exército brasileiro - nesta experiência de tempo radical da autobiografia, na qual passado e futuro fundam-se no agora - de se inserir em certa tradição militar constituída no mundo luso-brasileiro pelas reformas militares setecentistas.

\section{Uma família de militares}

Meu pai chamava-se Alexandre Manoel da Cunha Mattos, natural de Estremoz, no Alentejo, o qual era filho de Francisco Xavier de Mattos, Tenente do Regimento de Artilharia da mesma Província, nascido na cidade de Portalegre, e de Antonia Eugenia da Cunha, natural da vila de Borba. Minha mãe chamava-se Isabel Theodora Cecília Ignácia de Oliveira, natural da vila de Alegrete, e foi filha de João Fontes, nascido em Olivença, e Maria Eugenia, natural de Arronches. Estes são os nomes dos meus ascendentes de que tenho notícia, e entendo que nenhum pretendia qualificar-se como ramo de alguma grande família de Portugal. 
RaimundoJosédaCunhaMattosapresentou-seassimemsuasMemórias. Ele retratou-se então como um homem oriundo de família simples, constituída por soldados. Seu pai, Alexandre Manuel, foi soldado e assentou praça no Regimento de Artilharia de Estremoz tal como fizera seu próprio pai, Francisco Xavier. Raimundo José veio a ser parte da terceira geração da família a ingressar nos quadros da artilharia portuguesa. Antônio de Mattos Bento, bisavô paterno de Raimundo José, também servira nas tropas lusas, mas na milícia, chegando a capitão do Terço de Infantaria da comarca de Portalegre. ${ }^{9}$

As três gerações da família Cunha Mattos mencionadas nas Memórias conheceram realidades militares muito distintas. Francisco Xavier de Mattos era um soldado da 'antiga geração', cuja vida militar antecedeu ao projeto reformista do conde de Lippe. Seu filho Alexandre Manoel assentou praça nosegundoanodeimplantação dasreformasqueprometiam, entreoutros, a valorização do mérito pessoal na carreira militar e na concessão de premiações materiais e honoríficas. Raimundo José, por sua vez, serviu em outro momento de transição, que teve como pano de fundo a Revolução Francesa e as guerras napoleônicas.

\section{Francisco Xavier da Cunha Mattos}

A fidalguia era hegemônica na ocupação dos postos mais elevados em Portugal. ${ }^{10} \mathrm{O}$ pertencimento ao mais alto escalão da sociedade era uma credencial para se chegar ao generalato, embora não fosse a única. Os preten-

9 Antônio de Mattos Bento. Carta patente de 9 de setembro de 1726. Seção de Processos Individuais do Arquivo Histórico Militar de Portugal (AHMP), Lisboa, AHMP/DIV/3/7 - Mattos, Raimundo José da Cunha.

${ }^{10}$ Segundo Nuno Monteiro, houve uma alteração no que se refere às origens dos oficiais durante o comando de Lippe, quando a grande nobreza foi superada pelas locais e pelos oficiais estrangeiros. Contudo, aquele índice estaria mais relacionado à presença dos oficiais estrangeiros nos quadros militares portugueses do que ao acesso de pessoas sem distinção de nascimento aos postos do alto comando. Entretanto, já no período que antecedeu à queda de Pombal, foi percebida a recuperação dos índices de participação dos titulares nos postos de comando. MONTEIRO, Nuno. “Comandos militares e elites sociais." In: HESPANHA, António Manuel. Nova História militar de Portugal. Vol. II. Circulo de Leitores: Lisboa, 2004, p. 103-105. 
dentes aos ofícios militares deveriam demonstrar um mínimo de qualidades condizentes com a atividade guerreira, o que fazia com que os postos não chegassem a ser explicitamente hereditários.

Osgrupos intermediários da sociedade pouco se interessavam pela carreira das armas em Portugal. O predomínio da fidalguia no alto comando do Exército tornava difícil o progresso dos demais. Além disso, os postos de oficiais de baixa patente perdiam seu caráter de distinção social uma vezque os fidalgos reservavam grande parte deles a agregados de suasfamílias. Em tais circunstâncias, a carreira militartornou-seuma oportunidadedemobilidade social para os soldados advindos das camadas mais baixas. ${ }^{11}$

Nuno Monteiro mostrou o alargamento da nobreza portuguesa pela adoção da concepção de "nobreza civil ou política", levando à criação de "múltiplas e diversificadas fronteiras de estatuto no seu interior". A larga base da nobreza portuguesa era constituída a partir de critérios variáveis e locais, o que lhe concedia um caráter fluido e pouco eficaz na atribuição de distinção social no âmbito do reino, embora permitisse a mobilidade social numa cultura política "genericamente hostil" à sua ocorrência. ${ }^{12}$ Ascender aos postos de oficiais intermediários nas tropas de linha, ordenanças e milícias significava para homens vindos de camadas mais subalternas a possibilidade de alcançar a base da nobreza e ter acesso a outras formas de distinção, tais como os hábitos de cavaleiros das ordens militares. As armas foram o caminho para a ascensão social experimentado pelos Cunha Mattos.

Francisco Xavier de Mattos, avô de Raimundo José, alcançou o posto de $1^{\circ}$ tenente de uma importante praça militar após uma carreira relativamente curta, favorecido pela ampliação das forças a partir da Guerra de Sucessão de Espanha. Oseu sucesso foiapresentado nas Memórias comoresultado de seus méritos: "Meu avô paterno foi um dos mais instruídos oficiais da Escola de Artilharia do Alentejo antes da entrada do conde de Lippe em Portugal, e estou lembrado de ver em minha casa um grande número de manuscritos

11 COSTA, Fernando Dores. "Fidalgos e Plebeus"e "Guerra no tempo de Lippe e de Pombal.,'In: HESPANHA,António Manuel..Nova História militardePortugal.Vol.II.CirculodeLeitores: Lisboa,2004,p. 107. 12 MONTEIRO, Nuno Gonçalo. Elites locais e mobilidade social em Portugal nos finais do Antigo Regime. In: Análise Social, Lisboa, volume XXXII (141), p. 335-3681997 (2º). 
seus sobre matemáticas".13 Tal referência mostra o domínio de Raimundo José acerca da importância das matemáticas para a Artilharia de então e era credencial para a ocupação de postos nos regimentos. Francisco Xavier era, portanto, um soldado preocupado com sua instrução numa época em quea ignorância dos oficiais e de toda a nobreza portuguesa chocava os estrangeiros contratados para a organização do Exército, fato especialmente observado durante o governo do marquês de Pombal.

As qualidades intelectuais atribuídas a Francisco Xavier por seu neto resultaram deseusesforçospessoais, mastambém daexistência deuma"escola de artilharia" no Alentejo, ou seja, de um esforço do Reino de Portugal em oferecer formação mínima para o seu oficialato. As preocupações da Coroa portuguesa quanto à formação de seus artilheiros remontavam às Guerras de Restauração, quando fora criada em Lisboa, no ano de 1647, a Aula de Fortificação e Arquitetura Militar na Ribeira das Naus.

A expansão das aulas também ocorreu no reino a partir do decreto de 1701, que determinou a criação de Academias de Fortificação nas províncias do Reino de Portugal. O mesmo decreto abriu as aulas à frequência de oficiais dos regimentos e de nobresem geral, apesar deessas instituições terem como objetivo a formação de engenheiros militares. Os alunos militares que se destacassem teriam preferência na promoção aos postos.

A criação dessas aulas relacionava-se a um processo que, já em meados do século XVIII, levou a guerra a ser "pensada como uma tecnologia", segundo Rui Bebiano. Dessa perspectiva, o domínio de um conjunto completo de saberes permitiria a condução racional dos conflitos bélicose, por conseguinte, o controle de seus desdobramentos. Tal convicção estava associada ao meio intelectual em que circulavam os principais teóricos daquele século, quando houve uma revalorização da atividade militar e o início de sua profissionalização. Este processo duraria quase dois séculos e seria repleto de reveses. $^{14}$

${ }^{13}$ MATTOS, Raimundo José da Cunha. Memórias.

14 BEBIANO, Rui. "Os imaginários, os valores e os ideais da guerra." In: HESPANHA, António Manuel. Nova História militar de Portugal. Vol. II. Circulo de Leitores: Lisboa, 2004, p. 36-62. 
Francisco Xavier, assim, teve contato com a arte da guerra no período que antecedeu a participação de Portugal na chamada Guerra Fantástica. Naquela ocasião, ficaria patente que as breves iniciativas portuguesas não foram suficientes para a preparação de seus corposmilitares para umembate emmoldesmodernos. FranciscoXavierviu-seenvolvidona defesa doterritório português, sob o comando de oficiais estrangeiros, como parte de tropas despreparadas e com equipamentos obsoletos.

A vulnerabilidade bélica de Portugal levou Sebastião Carvalho e Melo, o conde de Oeiras e futuro marquês de Pombal, a buscar apoio estrangeiro, prioritariamente da Inglaterra. Entre as primeiras solicitações feitas ao aliadoinglêsestavaaindicação deoficiaisestrangeiros paraos postos decomando das tropas, iniciativa entendida como necessária diante da incapacidade dos oficiais portugueses de conduzirem um conflito segundo os parâmetros modernos da guerra. A nomeação de um comandante estrangeiro para as tropas portuguesas era também uma decisão política que favorecia o conde de Oeiras, pois evitava o surgimento de uma liderança militar de peso entre fidalgos portugueses que pudessem vir a disputar com ele as graças reais. A principal dessas indicações foi a do condeWilhelm von Schaumburg-Lippe, que deveria ocupar o posto de marechal-general do Exército português.

A contratação de oficiais e soldados era uma prática comum no cenário europeu, no qual homens que dominavam a 'ciência da guerra' disponibilizavam seus serviços a diferentes soberanos. Era em nome deste soberano, e não da nação, que os homens eram mobilizados e meios disponibilizados. Durante a Guerra Fantástica, Portugal contratou 54 oficiais, entre eles o marechal-general e dezesseis outros oficiais generais. ${ }^{15}$

Várias mudanças foram instituídas sob seu comando por alvarás e decretos, além deregulamentos, artigos deguerra, memóriase planosquepossuíam força de lei. Tratou-se de criar, assim, um novo repertório normativo organizado no período em que o conde de Lippe foi o marechal-general dos exércitos portugueses. A importância de se observar este repertório para as tropas foi confirmada pelo conde em 1773, em correspondência para Portu-

${ }^{15}$ MONTEIRO, Nuno. Op. Cit., 2004, p. 103 
gal quando estava em seu principado: "as Leis da Disciplina, da Tática e da Economia Militar formam o objeto essencial dos Regulamentos: da exata e contínua observância das Leise Regulamentoséque dependeo bomEstado das Tropas, isto é, sua Aptidão para a Guerra". ${ }^{16}$

As mudanças propostas por Lippe e seus apoiadores refletiram na vida ou, pelomenos, nas expectativas dos soldadosedo baixo oficialato deentão. Francisco Xavier da Cunha Mattos, por exemplo, teve seus últimos anos de serviço regidos pelo Plano de Artilharia organizado por Lippe, em 1763. Seu posto de primeiro-tenente da 6 a Companhia de Artilheiros do Regimento de Artilharia de Estremoz foi confirmado pela patente de 20 de julho daquele ano, passando a receber o soldo de 7.200 réis mensais, conforme estipulado. Também em obediência às determinações do conde de Lippe, ele seria reformado em 1764. ${ }^{17}$

Essa reforma resultou em dificuldades para Francisco Xavier, que ficou em situaçãofinanceirabastante delicada edependendo defavores dosfamiliares de sua esposa, uma vez que não existia ainda o Montepio: "como ele ficasse reformado por ocasião da Paz de 1763 e tinha vários parentes religiosos da Congregação dos Agostinhos Descalços, ficou recebendo uma ração do Convento desta ordem em Estremoz; é que minha Avó era engomadeira ou remendadeira (...) do claustro."18

A necessidade de medidas que garantissem a dignidade dos militares reformados-pelaidadeou poralguma ocorrência em serviçoquelhesimpedisse continuar na ativa - seria defendida no Regulamento dos Regimentos da Infantaria também criados por Lippe em 1763. Ele considerava que a situação humilhante em que muitos dos militares reformados se encontravam,chegandoaopontodedependeremdeesmolas,infamavaigualmentea corporação militar. No entanto, somente décadas depois seria criado o Mon-

\footnotetext{
${ }^{16}$ LIPPE.MemóriasobreosexercíciosdemeditaçãomilitarparaseremeteraossenhoresGeneraiseGovernadoresde Províncias. Lisboa: Oficina de João António da Silva, 1782, p. 3.

17 ANTT, Conselho de Guerra - Decretos. Decreto de 20 de julho de 1763 e Decreto n. 138 de 1 de setembro de 1764 , respectivamente.

${ }^{18}$ MATTOS, Raimundo José da Cunha. Memórias.
} 
tepio, em 1795, para garantir o sustento dos familiares no caso de morte dos militares.

Apremiaçãodossoldadoseoficiaisquedesempenhavambemsuasobrigações era outra das propostas das reformas. Nesse sentido, o Plano de ArtiIharia de 1763 determinava que os"oficiais portugueses das Companhias de Bombeiros, Mineiros e Artilheiros" que se distinguissem por seus estudos e préstimos seriam gratificados com aumento dos vencimentos. Tal aumento seria gradual e proporcional ao conhecimento "que cada um mostrar"ao ser submetido a um "rigoroso exame da sua ciência", que viria a ser chamado de oposição. Àqueles que dominassem "perfeitamente o que pertencer às suas diversasaplicações"seria concedido o dobro dos soldos. Era a promessa, portanto, do início de novos tempos, nos quais o mérito seria recompensado. ${ }^{19}$ Contudo, os bons serviços e o esforço pessoal para a aquisição de conhecimentos por parte de Francisco Xavier, conforme testemunho de seu neto, não foram recompensados em termos materiais, e ele acabou dependendo dos vínculos familiares e do trabalho de sua esposa para obter o sustento, como visto anteriormente.

\section{Alexandre Manoel da Cunha Mattos}

A situação delicada em que se encontrava Francisco Xavier não desmotivou seu filho, Alexandre Manoel, a assentar praça na Companhia de Artífices do mesmo regimento em que ele servira. Oestatuto militar daquela companhia fora confirmado pelo Plano da Artilharia de 1763, que determinou, entre outros, a obrigatoriedade do uso dos uniformes militares pelos Artífices, que estavam "sujeitos às mesmas leis e à mesma Disciplina Militar". Eram atribuições da Companhia a manutenção e construção das fortalezas e dos fortes; a feitura, organização e administração dos apetrechos bélicos; a construção das pontes nas campanhas - atribuição específica dos pontoneiros - e o embarque e desembarque dos provimentos, entre outras.

${ }^{19}$ Conde de Lippe. Plano de Artilharia. Disponível em: http://www.iuslusitaniae.fcsh.unl.pt/verlivro. php?id_parte=108\&id_obra=73\&pagina=45, acessado em 27/12/2015. 
Alexandre Manoel optava, assim, por entrar nas tropas em uma companhia criada no contexto das reformas e que, potencialmente, oferecia significativas oportunidades de promoção. Durante a guerra do ano anterior, a falta de conservação e de reparos dos edifícios militares e das muralhas havia sido considerada um grave obstáculo para a defesa das praças de guerra, agravado pela recusa dos soldados em cumprir tais tarefas. Daí a necessidade de atribuir a uma companhia específica a função de construir e manter a infraestrutura militar. Pode-se compreender a escolha dessa Companhia recém-criada como estratégia de aceleração de promoções por partedeAlexandre Manoel. Estratégia essa, contudo, que viria a fracassar.

Podemos inferir que a presença de Lippe e suas propostas ampliaram as expectativas de benefícios para os que entravam nas tropas, o que deve ter sido particularmente sentido durante o período em que o conde conduziu pessoalmente suas reformas, sob os auspícios do poderoso conde de Oeiras. AlexandreManoelserviuemumregimentoespecialmenteinfluenciadopelas propostas reformistas uma vezque estava sob o comando deValleré, um dos principaiscolaboradoresdeLippenoprojetodeaculturaçãomilitardastropas lusas. Oficial de grande notoriedade, Valleré foi um dos poucos estrangeiros quemantiveramseuspostosdecomandocomoadventodachamadaViradeira.

Os oficiais estrangeiros atuaram, desde o início da campanha, como agentes multiplicadores de uma nova postura militar cuja marca principal era a disciplina das tropas. A ação dos oficiais seria crucial, já que era deles a responsabilidade pela disciplina de seus subordinados. Aautoridadedoscomandantes detodasas patentes deveria serlegitimada pelo preparotécnico, pela capacidade de liderança, pela retidão do caráter, pela disciplina e pela obediência aos superiores eàs determinações normativas - qualidades que nãoeramgarantidaspelonascimento, masconsequênciasdoesforçopessoal de cada oficial.

A relação entre nobreza e oficialato, aliás, aparece invertida nos novos regulamentos.Enquantotradicionalmenteaorigemnobrepraticamentegarantia a ocupação de um alto posto militar, na perspectiva dos regimentos, 0 cumprimento dodeverpoderia nobilitarooficial:"devendo oponto dehonra 
animar aos Oficiais mais do que algum outro motivo, todo o Oficial de Patente assinada pela Real Mão será reputado nobre".20

Essas aspirações resultaram em confrontos com os representantes da velha ordem. Os generais portugueses que se viam como proprietários de ofícios foram os maiores críticos de tais propostas, e entraram em sérios confrontos com os'oficiais profissionais', cujos comportamentos eram considerados atos de desrespeitoàs suas dignidades. Oapoio dadoa Lippepeloconde de Oeiras impediu a ocorrência de resistências mais explícitas enquanto liderava diretamente as tropas, mas os oficiais descontentes boicotavam, no cotidianodeseusregimentos, muitasdasordensdomarechal-general,numa espécie de resistência passiva.

Para Lippe e seu ajudante-general, Johann Friedrich Böhm, os oficiais lusos eram despreparados e agiam guiados por grande má-vontade, originando-se aí a indisciplina geral das tropas. A resistência dos oficiais era um grande obstáculo, pois a eles eram atribuídas a manutenção da ordem e a preparação das tropas, o que exigia a constante observação dos subordinados. A rede de vigilância contaria com instrumentos criados com o intuito de manter o alto escalão constantemente informado sobre as condições das tropas. Entretais instrumentos estavam os relatórios com informações sobre os oficiais, os mapas dos efetivos e os livros de regimentos. Tais recursos permitiriam o controle à distância. Os exercícios de campo seriam o teste final do estado das tropas, assistidos pelo próprio soberano.

Estar sob o comando de oficiais particularmente empenhados na reforma era, assim, um ponto significativo na experiência de um militar de então e Valleré não seria o único estrangeiro a comandar Alexandre Manuel. Em 1774, a companhia dos Artífices foi transferida para a cidade de Faro, no Algarve,regimentoparticularmenteinfluenciadopelaaçãodaquelesoficiais, tendo sido comandado, entre 1764 e 1774, por Christian Frederich von Weinholtz, principal tradutor da correspondência do conde após seu retorno a seu condado. No comando do regimento, Weinholtz foi substituído pelo

${ }^{20}$ LIPPE,condede.RegulamentoparaoexercícioedisciplinadosregimentosdeinfantariadosexércitosdeSua Majestade Fidelíssima. Lisboa: Secretaria de Estado, 1763, p. 163. 
coronel James Ferriere pelo tenente-coronel Simon Frazer, amboschegados a Portugal durante a guerra de 1762. O afastamento dos oficiais estrangeiros fez com que o comando do regimento passasse para o tenente-coronel José Nunes da Costa Cardoso (1776-1783) e, posteriormente, para o brigadeiro Teodósio da Silva Reboxo (1783-1807), ambos reconhecidos pelos seus conhecimentos técnicos e pela rigorosa preocupação com a disciplina. Entrementes, Alexandre Manoel serviria no Arsenal Real do Exército, em São Julião da Barra, entre 1778 e 1790, enquanto a Companhia de Artífices e Pontoneiros do Regimento de Faro esteve ali empregada nas obras noTrem de Artilharia.

A proximidade com tais oficiais, contudo, não parece ter facilitado a ascensão profissional de Alexandre Manoel. Raimundo José não destacou evento algum mais significativo nas poucas referências que fez à carreira do pai. De fato, ao retratá-lo, parece pretender demonstrar as dificuldades que elehaviaenfrentadoe,consequentemente, a parcialidadedosresultadosdas reformas do comandante prussiano.

A documentação localizada acerca da carreira de Alexandre Manoel mostra que sua progressão foi bastante lenta, a despeito da mencionada estratégia de adentrar em uma companhia recém-criada. Atuando como militar durante 55 anos, morreu no posto de tenente, ou seja, na mesma posição em que seu pai havia sido reformado após apenas 28 anos de tropa, apesar das atestações muito positivas feitas por seus superiores, que o retrataram como cumpridor de seus deveres.

Mesmo tendo Raimundo José retratado seu pai como um soldado com poucas recompensas pelos serviços prestados, Alexandre Manoel foi condecorado com o Hábito da Ordem de Santiago da Espada em 1798, o que lhe conferia prestígio. ${ }^{21}$ Dezanos antes, as ordens militares haviam recebido novos regulamentos, comoobjetivo deadequá-lasaosnovostemposereforçar a sua"decência e dignidade".Tais regulamentos determinavam que o hábito da ordem de Santiago fosse, 'em regra', destinado aos "magistrados, até o lugardo desembargadordosagravos". Contudo, ficou aberta a possibilidade

${ }^{21}$ ANTT, Decretos do Ministério do Reino, maço 60, ano 1798, processo 420. 
de ser usado na premiação de "outros serviços que parecerem dignos dela, segundo a qualidade e importância das pessoas, dos empregos e dos serviços."22 O pedido de mercê do Hábito de alguma ordem militar apresentado porAlexandreManuelfoireforçadopelostestemunhos deseusbonsserviços, comprovadospordiversosatestadosdeseussuperiores, pelotempojápassado nas tropas e pelos serviços prestados por seu pai, Francisco Xavier.

Em uma dessas declarações, o sargento-mor da artilharia no Arsenal Real dos Exércitos, Rodrigo Lobo Pimentel de Vabo, informou detalhadamente sobre o cotidiano das atividades desempenhadas por Alexandre Manoel quando era furriel sob seu comando no Algarve, no ano de 1794:

Certifico que sendo eu Capitão e Comandante da Companhia de Artífices e Pontoneiros da Artilharia do Algarve, destacada na Corte, era nela Furriel de Pontoneiros Alexandre Manoel da Cunha Mattos, o qual, por nomeação minha e aprovação do llustríssimo e Excelentíssimo Senhor Duque de Lafões, Marechal-general dos exércitos de Sua Majestade Fidelíssima, e junta à Sua Real Pessoa, passou a Furriel de Artífices em que o propus, pelo achar tão pronto nas suas obrigações, servindo a Sua Majestade com Grande desembaraço, atividade, zelo, préstimo, obediência, agilidade, enfim, com muita honra e recomendável conduta, de sorteque em muitas diligências particularese circunstanciadasemqueoencarregueiem postos destacadosqueelecomandou nas muitas e diferentes fainas e trabalhos de lidar com Artilharia, embarcando-as e desembarcando-as nas Naus e Fragatas de Guerra dos Navios que as traziam de fora, na fatura e construções dos Espaldões no Alfeite para a prova das peças novas; na arrumação dos trens, parques, armazéns, pilhas de balas, conduções ediligências de pólvora, eem tudo o mais concernente atãoimportante serviço de que o dito Furriel era encarregado, e de que eu o incumbia, sempreacheineleumadistintaresponsabilidadeedesempenhodasuaobrigação [...] Lisboa, quatorze de setembro de $1794 .{ }^{23}$

O contraste entre a carreira de Alexandre Manoel e a de seu filho é enorme. Raimundo José ocupava um posto superior ao do pai já em 1798, quando foi promovido a tenente. Cinco anos depois, seria capitão do Regimento de Artilharia de São Tomé. O serviço em alguma possessão ultra-

\footnotetext{
${ }^{22}$ Alvará de 19 de junho de 1789. Disponível em http://www.iuslusitaniae.fcsh.unl.pt/verlivro. php?id_parte=109\&id_obra=73\&pagina=817, acessado em 27/12/2015.

${ }^{23}$ Idem, ibidem.
} 
marina significou para muitos soldados a oportunidade de alcançar postos militares mais altos: foi esse o caminho escolhido por Raimundo José.

Diante do exemplo de seu filho, que se encontrava em Lisboa gozando delicença,ecertamente poreleestimulado, AlexandresolicitouaoConselho Ultramarino o posto de capitão-mor da Ilha de São Tomé, em janeiro de 1805. Seu pedido foi justificado em termos do longo tempo de serviço e da qualidade das tarefas por ele executadas. A necessidade de superar a difícil situaçãoem que seachava,"muito pobre,obrigadoa sustentar sua numerosa família, e com poucos meios de o poder conseguir com honra", também foi evocada. Por fim, Alexandre Manuel observaria que seu filho encontrava-se servindo como comandante da fortaleza de São Sebastião naquela ilha. ${ }^{24}$

Nesta ocasião, os seus superiores diretos reafirmaram, em conjunto, a competênciaearesponsabilidadedaqueleoficialsubalterno:nãoapenasera cumpridor de suas obrigações, como das responsabilidades que iam para alémdeseuposto, mantendoseussubordinadosemconstanteprontidãopara a defesa dos interesses reais. Porfim, declaram que otenente comportava-se "com muita honra, zelo do Real serviço, exemplar conduta, e por tudo digno do nosso crédito e merecedor de qualquer graça que seja servido fazer-lheS. A. R... O documento foi assinado pelos tenentes-coronéis Rodrigo Pimentel do Vabo, José Nunes da Costa Cardoso e Carlos Julião. Apesar de todo esse apoio, o pedido foi indeferido.

Em 1810, Alexandre Manoel teve outra oportunidade de demonstrar seus méritos. O então coronel-de-artilharia Manoel Ribeiro de Araújo incumbiuaosegundo-tenentea missão de "comandar efetivamente a Guarda, que então se destinou para segurança dos Armazéns do Forte". Tal serviço durou 258 dias e foi desempenhado com "a maior atividade e inteligência", estandoelesempreprontoaocumprimentododever.Aconfiançadocoronel nessesubordinadojustificava-sepelas"provasevidentes"desuashabilidades, subordinação e prontidão no serviço do arsenal. Foi também considerado "muito fiel e zeloso na boa arrecadação e segurança da Real Fazenda". Além dessas virtudes no desempenho de suas obrigações militares, era também

${ }^{24}$ Alexandre Manoel da Cunha Mattos. AHU_CU_070_CX 38 , D 1. 
merecedor de respeito devido a "exemplar conduta civil, qualidades que o fazem preferível para ser empregado em diligências de ponderação".25

A última representação feita por Alexandre Manoel dizia respeito à sua promoção para capitão. A portaria que encaminhava a representação e os respectivos documentos "aos governadores do reino de Portugal e dos Algarves", responsáveis pela aplicação dos exames exigidos para a efetivação das promoções, foi assinada em 7 de outubro de 1817. Em 19 de novembro do ano seguinte, Alexandre Manoel faleceria sem que tal promoção tivesse sido concedida. Seu Montepio, conquista dos militares, ficaria para sua filha Rufina.

\section{A vez de Raimundo José}

A trajetória profissional de Raimundo José foi muito diferente de seus antepassados. Para isso, três aspectos foram de suma importância: a educação formal recebida na Casa Pia de Lisboa e nos Regimentos de Artilharia, sua iniciativa de ir para o além-mar, especificamente, para a periférica São Tomé e Príncipe, e os conflitos que agitaram o mundo ocidental a partir do último quartel dos setecentos. Conflitos esses que exigiram de Portugal grandesesforçosbélicos,oaumentodosefetivose,consequentemente, acriação de novos postos de comando. A geração de militares à qual pertencia Raimundo Josévivenciou o aumento das expectativas de mobilização social pelas armas.

Ao se dar crédito à imagem construída por Cunha Mattos sobre seu pai, esseesteve bastante desiludido quanto aos benefícios do serviço militar. Longe dos esforços de guerra, a importância da melhoria das armas pouco encontrava eco entre os grandes do reino. Esta foi uma realidade conhecida pelo próprio Lippe e confidenciada em sua correspondência com os interlocutores que mantivera em Portugal.

A frustração com sua trajetória teria levado Alexandre Manoel a oferecer a seu filho uma educação que o permitisse seguir carreira longe das armas:"Meu Pai, reconhecendo o pouco que nesse tempo [1784] prometia

${ }^{25}$ Idem, AHU_CU_070_CX 38,D 1.Certidão datada de 20 de maio de 1811. 
a carreira militar, e lembrado dos desfavores da fortuna, tanto contra meu Avô como contra ele mesmo, decidiu-se a que eu me aplicasse à cirurgia...."26

Para isto, Alexandre Manoel esforçou-se para matricular Raimundo José no Colégio São Lucas, da Casa Pia de Lisboa. Instituição criada para receber marginaisdasociedadeportuguesadeentão, anotoriedadedaCasaPia,contudo,foialcançadacomotrabalhodeinstruçãorealizadocom criançasejovens. Nesseaspecto, destacavam-seos colégios S.Josée oSão Lucas Evangelista.. ${ }^{27}$

José Bonifácio de Andrada e Silva considerava a criação da Casa Pia como um dos grandes feitos de d. Maria I. Ali, os mais desvalidos filhos da soberana eram "instruídos nos Elementos das Ciências e das Belas Artes" e de onde alguns de seus egressos "foram brilhar em Coimbra e na Itália," afirmou em sessão da Academia Real das Ciências de Lisboa. ${ }^{28}$

Diogo Ignácio de Pina Manique foi o idealizador e maior protetor daquela instituição, que veio a ser um dos braços da Intendência Geral de Polícia da Corte e Reino. Os programas de tais colégios contemplavam conteúdosbastanteinovadores, algunsdelesoferecidosapenaspelaUniversidadede Coimbra e pelo Real Colégio dos Nobres. A ousadia do projeto e o sucesso alcançadopordiversosegressosdeveram-seprincipalmenteàatuaçãodeJosé Anastácio da Cunha na organização dos estudos e ao empenho pessoal do intendente.Épertinente para otrabalhopresenteobservarqueamaiorparte dos professores do Colégio São Lucas, no período em que Cunha Mattos lá esteve, era formada pormilitares, e, mais especificamente, por artilheiros. Algunsdelesseriam promovidosaaltos postosdooficialatonaviradadoséculo, enquanto outros ingressaram na Academia Real das Ciências e ocuparam importantesempregosrégiosemáreastécnicas.Muitostinhamsofridocoma

26 MATTOS, Raimundo José da Cunha. Memórias.

27 RODRIGUES, Neuma Brilhante. "Para a utilidade do estado e "glória à nação": a real casa pia de Lisboa nos tempos de Pina Manique (1780-1805)". In: RevistaTerritórios e Fronteiras, Cuiabá, vol.1 N.2 - Jul/Dez, p. 23-41, 2008. Disponível em: http://www.ppghis.com/territorios\&fronteiras/ index.php/v03n02/article/view/15.

28 SILVA, José Bonifácio de Andrada e Silva. Elogio acadêmico da Senhora d. Maria Primeira, recitado por José Bonifácio de Andrada e Silva em sessão pública da Academia Real das Sciências de Lisboa, aos 20 de março de 1817. Typographia Imparcial de Francisco de Paula Brito: Rio de Janeiro, 1839. 
inquisição, tal como ocorrera com o próprio Anastácio, ele mesmo oficial da ArtilhariaefortementeinfluenciadopelosoficiaisvindoscomcondedeLippe. ${ }^{29}$

$\mathrm{Na}$ Casa Pia, Raimundo José dedicou-se à cirurgia, em observância aos planos traçados para ele por seu pai:

Meu Pai (...) decidiu-se a que eu me aplicasse à cirurgia para ao depois estudar Medicina na Universidade de Coimbra, ou ir frequentar as grandes Escolas de Edimburgo, Londres ou Copenhague, para onde haviam ido alguns colegiais, que muito honraram o Estabelecimento Patriótico da Casa Pia do Castelo de São Jorge. Com efeito (...), [estudei]Latim, Francês, Inglês, Anatomia e Cirurgia, umas coisas no Colégio e outras no Hospital de São José, cujas aulas íamos frequentar: não fui dos melhores estudantes, mas era tido como um dos mais aplicados. ${ }^{30}$

Cioso por sua imagem de estudioso, Cunha Mattos observou em suas Memóriasque, senãotevecondições declassificar-seentreosalunos daCasa Pia que brilharam na República das Letras, não lhe faltou o mérito do esforço.

Em 1790, Alexandre Manoel voltou para o Algarve em decorrência de mais uma transferência da Companhia de Artífices do Regimento de Artilharia de Faro, na qual servia. Decidiu levar consigo o filho mais velho, deixando o resto da família em Lisboa. Resolveu também que Raimundo José deveria entrar como soldado voluntário no mesmo regimento em que servia.

Os estudos de Cunha Mattos, seriam, assim complementados na cidade de Faro. Ele continuou a dedicar-se à cirurgia no hospital militar da cidade, tendoconseguido para isso autorização do comandante do regimento.Com a chegada dos rumores sobre a possibilidade de Portugal ver-se envolvido numa nova guerra em decorrência dos acontecimentos na França, abandou definitivamente a área médica:

Todos conheceram que mais cedo ou mais tarde teríamos guerra, e por isso eu entendi que seria mais vantajoso fazê-la como militar combatente com as Armas na mão do que como Facultativo de saúde, tratando os enfermos nos

29 Sobre o currículo dos professores de Raimundo José no ano de 1783 na Casa Pia, ver Rodrigues, Neuma Brilhante. Op. Cit, p. 37-39.

30 MATTOS, Raimundo José da Cunha. Memórias. 
Hospitais. Este meu juízo passou a ter execução e consequentemente larguei os Estudos Médicos e passei a frequentar os estudos militares na Aula do Regimento de que era Lente o Tenente Coronel José Nunes da Costa Cardoso. ${ }^{31}$

As armas, portanto, foram opção sua quando chegou à fase adulta, na expectativa da participação em um novo conflito e de abertura de novas oportunidades decorrentes da mobilização para o embate. A atuação como cirurgião do Exército era, para usar uma expressão de Cunha Mattos, "menos militar", e parece que isso não lhe agradava. A ênfase dada em suas Memórias ao fato de ter passado de 'aluno esforçado' de cirurgia a um dos mais destacados aspirantes de artilharia do seu regimento, indica tanto a possibilidade de ter encontrado sua vocação na nova carreira comoa grande motivação do iminente combate.

A formação recebida na Casa Pia seria enriquecida nas aulas do regimento, nas quais adquiriu conhecimentos técnicos necessários ao bom desempenhodesuasnovasfunçõesnaartilharia.Aquelasaulasforamcriadasno contexto da guerra de 1762 e confirmadas pelas reformas militares de Lippe.

As escolas regimentais faziam parte do conjunto de instituições laicas de ensino criadas por Pombal. Seguiam uma concepção prática do conhecimento, oferecendo aulas técnicas especificamente destinadas a capacitar os soldados para o bom desempenho de suas atividades e eram abertas a civis interessados em matemática e engenharia. As aulas teóricas e práticas abordavam temascomoa movimentaçãonos campos debatalha, a coleta de informações e o mapeamento de terrenos e regiões.

A criação de aulas dessa natureza para o Regimento de Artilharia da Fortaleza de São Julião da Barra, em Oeiras, foi determinada pelo alvará de 9 de abril de 1762, portanto, antes da chegada de Lippe e seus oficiais. Os soldadosseriamobrigadosafrequentaras duashorasdeaulasoferecidastrês vezes por semana. O recebimento dos soldos ficava vinculado ao cumprimento dessa obrigação. A promoção a postos superiores como ode sargento seria vedada àqueles que não apresentassem a"certidão de exame feito pu-

${ }^{31}$ MATTOS, Raimundo José da Cunha. Memórias. 
blicamente por Professores da mesma Artilharia, na presença do General desta Corte e Província". Os professores responsáveis pela aula eram oficiais indicadospela JuntadosTrêsEstados, com vencimentosiguaisaos domestre da Aula de Estremoz e pagos em acréscimo ao soldo relativo ao posto. ${ }^{32}$

Com o início da guerra Fantástica, tal proposta não foi colocada em prática. No ano seguinte, contudo, foi aprimorada pelo conde de Lippe e agregadaaoPlanoqueSuaMajestademandaseguireobservarnoestabelecimento,estudoseexercíciosdasaulasdosRegimentosdeArtilharia. ${ }^{33}$ Haviaapreocupaçãodeque os artilheiros dominassem os conhecimentos exigidos para a manipulação e manutenção dos armamentos, obrigações que levariam a artilharia a ser considerada a arma acadêmica.

A artilharia, arma na qual os Cunha Mattos serviram, mereceu atenção especial do conde. Ele considerava que dela dependia, cada vez mais, o poder de um exército. Isso exigia uma primorosa formação dos soldados e oficiais, ea perfeição das tropas dependia de uma capacitaçãoespecífica que abrangesseconhecimentosdequímica, aritmética, trigonometria, topografia e edificação, entre outros.

Durante as aulas, os oficiais dos regimentos também deveriam instruirse nas questões relativas a seus postos. Deveriam ser capazes de formulare executarplanosdeataqueededefesaassimquelhesfossemsolicitados,oque exigia conhecimentos dos "Parques e Equipagens da Artilharia de todas as espécies e operações dela". ${ }^{4}$

Os professores eram escolhidos dentro do próprio regimento e nomeadospelosoberanoeseriamresponsáveispelatraduçãoeexplicaçãodasobras

32 Alvará de 19 de abril de 1762, criando o Regimento de Artilharia da Corte, disponível em: http:// www.iuslusitaniae.fcsh.unl.pt/verlivro.php?id_parte=105\&id_obra=73\&pagina=1215, acessado em 8/10/2015.

${ }^{33}$ Conde de Lippe. "Plano que Sua Majestade manda seguir e observar no estabelecimento, estudos e exercícios das aulas dos Regimentos de Artilharia, de 15 de julho de 1763". In: Collecção da legislaçãoportuguzadesdeaultimacompilaçãodasordebações,redigidapeloDesembargadorAntónioDelgadoda Silva. Legislação de 1763 a 1774. Lisboa: Typographia Maigrense, 1829, p.47.

${ }^{34}$ Conde de Lippe. Loc. Cit. 
indicadas no plano. Por tal trabalho, além do soldo relativo aos postos que ocupavam, recebiam 20 mil réis por mês.

O conde de Lippe definiu os conteúdos e os livros que deveriam ser usados pelos alunos. A Secretaria dos Negócios Estrangeiros e da Guerra deveria providenciar a tradução e publicação das obras que não estivessem em português. Qualquer alteração na lista oferecida pelo conde de Lippeera veementementerejeitada.Anosdepois,ocondeflexibilizoutaldeterminação e indicou a criação de bibliotecas especializadas nos regimentos.

Os artilheiros tinham aulas de matemática, bombardeio, composição defogos de artifício, engenharia efortificação, minas e bombas, operações e manobras. Os livros usados em tais aulas eram todos estrangeiros, trabalhos reconhecidos e amplamente usados nas escolas congêneres internacionais. Havia um predomínio da literatura militar francesa.

O reconhecimento dos autores selecionados não impediu que as escoIhas de Lippe fossem criticadas. Em 1764, José Anastácio da Cunha considerou que a obra de Dulacq, usada nas aulas de bombardeio, continha erros. ${ }^{35}$ Mas, apesar das ponderações de Anastácio, que chegaramao conhecimento do marechal-general, a lista de livros determinada por Lippe continuou em vigor durante décadas.

Em 1786, o brigadeiro e comandante do Regimento de Artilharia da Corte, Christianno Frederico de Weinholtz, enviou à Secretaria da Guerra o pedido de substituição de algumas daquelas obras em decorrência de te-

35 O episódio da análise dessa obra é bastante curioso: “Pediu-me o capitão de mineiros do meu regimento a minha opinião sobre o que vários autores tinham publicado acerca das minas: dei-lha por escrito muito sem segunda intenção que nem deixei em meu poder cópia. Entre outras coisas mostrei alguns erros de Mr. Dulacq, autor que o marechal [conde de Lippe] tinha recomendado aos artilheiros e engenheiros, o que nem eu nem talvez pessoa alguma do meu regimento então sabia. Depois passando o marechal por Almeida, aonde eu estava, houve quem inocentemente e cuidando que me fazia um grande bem, ofereceu a minha dissertação ao conde de Lippe, que naturalmente se julgou insultado. Apesar de partir então para Buckemburg ainda duvidoso da minha inocência, deixou recomendado que se me dobrasse o soldo e me adiantassem." (apud. QUEIRÓ, João Filipe. José Anastácio da Cunha: um matemático a recordar, 200 anos depois". In: BoletimdaSociedadePortuguesa deMatemática, n²9, setembrode 1994,p.2.Disponívelem: http:// www.mat.uc.pt/ jfqueiro/cunha.pdf , consultado em 02/04/2015. 
rem se tornado obsoletas. Solicitou, entre outras mudanças, que o Curso de Matemática de Bellidor fosse substituído ou, pelo menos, que sua tradução, repleta de erros, fosse corrigida. Argumentou que aquele era o momento mais adequado para fazê-lo, pois a edição estava esgotada.

Além disto, continuava o brigadeiro, o livro de Bellidor tinha 40 anos de uso na França quando fora adotado em Portugal. As escolas de artilharia e da marinha francesas já estavam usando os cursos organizados por Bezout, especialmente para elas. Essasobrasseriam muito maiscompletas, atualizadas e perfeitamente adequadas aos estudos militares. Ele solicitava que elas fossem adotadas em Portugal, onde já se encontravam traduzidas e publicadas pela Universidade de Coimbra. Seu pedido só veio a ser aceito após longas ponderações e a ampliação da lista foi autorizada. ${ }^{36}$

Raimundo José da Cunha Mattos, a despeito deste debate, considerava que as aulas haviam sido decisivas em sua vida profissional:

Com efeito, apliquei-me às Matemáticas pelos compêndios do Mr Bellidor de que se fazia uso na nossa aula, eao mesmo tempo frequentava os exercícios de Infantaria e Artilharia em que o meu Regimento era deputado superior aos da sua Arma em razão do zelo e autoridade do seu chefe, Brigadeiro Reboxo. ${ }^{37}$

DeBellidor,éprovávelqueRaimundotenhaestudado:Novocursodematemáticaparausodosofficiaesengenheirosed'artilheria,BombardeiroFrancezeSciencia dosEngenheiros, todospertencentesàlistadelivrosdefinidaspordeLippeem 1763. A lista do conde contava ainda com obras de Lacq, Saint-Remy, La Valiére, Lorm e Vauban. ${ }^{38}$

O Regimento de Artilharia de Faro alcançou excelente reputação sob a direção do brigadeiro Reboxo, oficial mencionado por Raimundo José. Os artilheiros formados nas aulas e nos exercícios práticos sob seu comando eramconhecidoscomosoldadosvalorososepossuidores deconhecimentos

${ }^{36}$ Christianno Frederico de Weinholtz. Requerimento do Brigadeiro Christianno Frederico de Weinholtz, 1786. AHMP, Lisboa, 3/5/2/24.

37 MATTOS, Raimundo José da Cunha. Memórias.

${ }^{38}$ Conde de Lippe."Plano que Sua Majestade manda seguir e observar no estabelecimento, estudos e exercícios das aulas dos Regimentos de Artilharia..., op. Cit, p. 47 
preciosos. Aelaboração de mapase de descrições geográficas tambémeram atividadesdesempenhadascommaestriapelossoldados:omapeamentodo Algarve foi, em grande parte, realizado por eles. Vários dos soldados oriundos daquele regimento foram admitidos na Academia da Marinha. Segundo JoãoLopes,emsuaCorografiaoumemóriaeconômica,estatísticaetopográficadoReino doAlgarve, aricaproduçãocartográficadesseregimentoestavadepositadaem bibliotecas e arquivos de Lisboa. ${ }^{39}$

A produçãocartográfica deentãoestava inseridanapropostadereordenamento político e espacial do território português, promovido no governo ded.Maria.A proposta intervencionista, comatuação direta doministroJosé de Seabra da Silva, dependia do conhecimento do território, que deveria ser representado em uma novo mapa geográfico e militar do Reino. Foram promovidosentãolevantamentoscorográficosetopográficos,àsvezesacompanhadasporinformaçõesestatísticasememóriasexplicativas, algumascomreferênciasàhistóriadaocupaçãodaslocalidades, mascomênfasenopresente. ${ }^{40}$

A influência destas atividades na carreira de Cunha Mattos é marcante. Parte considerável de sua produção intelectual, cuidadosamente publicada por ele no primeiro quartel do oitocentos, seria dedicada a corografias e itinerários. ${ }^{41}$ NaspáginasdasMemóriasencontram-seanotaçõessobreoteatro deguerra do Rossilhão, comesboços de mapasedos movimentos das tropas esboços dos terrenos, das cidades e de alguns dos movimentos militares. Representações essas elaboradas décadas após a guerra a partir das anotações feitas pelo autor em suas cadernetas que levou para os campos de guerra do Rossilhão e da Catalunha.

39 LOPES,JoãoBaptistadaSilva.Corografiaoumemóriaeconômica,estatísticaetopográficadoReinodoAlgarve. Academia das Ciências de Lisboa: Lisboa, 1841, p. 74. Efetivamente, encontram-se na Biblioteca Nacional de Lisboa três plantas de instalações militares do Algarve atribuídas a Teodósio Reboxo.

${ }^{40}$ MARTINS,Carlos Henrique.Oprograma deobras públicas parao Portugal continental, 1789-1809.Vol. II. Tese de Doutoramento em Arquitetura, Universidade de Coimbra, 2014, p.571. Disponível em: https://estudogeral.sib.uc.pt/handle/10316/25713

${ }^{41}$ Sobre as corografias de Cunha Mattos, ver Kaori Kodama. Itinerários, corografias e escritas da história: as viagens e os registros de Raimundo José da Cunha Matos no Império do Brasil. Escritos. Revista da Fundação Casa de Rui Barbosa. Ano 2, n. 2, 2008, p. 373-395. 
RaimundoJoséconsideravasuapassagemporaqueleregimentodoFaro uma experiência significativa, mencionada frequentemente em diferentes momentos de suas Memórias ou nas solicitações de promoção ao longo de sua carreira. $\mathrm{O}$ orgulho de pertencer àquele corpo ficou evidente no relato que fez do encontro com um senhor -"a quem chamavam Doutor"- que se admirou com seu conhecimento sobre as obras de Bellidor, Bureau e Euclides, com sua familiaridade com as línguas francesa einglesa e porele possuir "outrosestudosquerarasvezesseencontravamnaqueletempo(ehojemenos ainda) em um simples soldado de 16 anos de idade." ${ }^{42}$ Cunha Mattos fez questão de responderqueoseu nãoera um caso isolado:naquele regimento existiammuitosoutrosestudantesmelhoresqueele,etodosaspirantesapostos de general.

O conhecimento ali adquirido foi apontado por ele como a principal razão para sua primeira promoção a cabo de esquadra, já no contexto da mobilização para a Guerra do Rossilhão e da Catalunha, ocorrida entre 1793 e 1795. Os regulamentos da artilharia portuguesa previam comocritérios para ascensão na carreira o tempo de serviço e a aprovação em exames. Os resultados desse pretendido rigor seriam comprovados, segundo Cunha Mattos, pela superioridade das tropas portuguesas em relação às espanholas.

Ele explicou os sucessos alcançados pela Divisão Auxiliadora como decorrentes, em grande parte, da qualidade de seus oficiais. Entre esses, d. Francisco Xavier de Noronha mereceu especial consideração nas páginas dasMemórias, sendodescritocomo“inseparávelcompanheirodenossossoldados". O seu mérito foi reconhecido pelo príncipe regente, que o premiou com a patente de tenente-general ao final da guerra e o designou para importantes ofícios nos anos que se seguiram, inclusive o de membro da Junta Administrativa encarregada de reger o reino de Portugal entre a partida de d. João Vl e a chegada de Junot.

Cunha Mattos listou o "general d. António Soares de Noronha", o "marechal d. Francisco Xavier de Noronha" e o "coronel Gomes Freire" como os únicos oficiais que haviam participado de algum confronto bélico ante-

42 MATTOS, Raimundo José da Cunha. Memórias. 
riormente à campanha do Rossilhão e da Catalunha, os dois primeiros sob o comando do conde de Lippe, e Gomes Freire como voluntário a serviço da Rússia. "Os demais não tinham conhecido a guerra, mas a vontade de atuarem com honra e determinação levara a uma ação honrosa." Ele silenciava quanto aos demais que atuaram em campanhas fora de Portugal, nos exércitos dos reinos aliados, e os que estiveram sob as ordens de Lippe na Guerra Fantástica.

Ele associava, vale também destacar, bom desempenho militar e honra. Tal associação remontava ao período em que a própria existência da nobreza legitimava-se porsuas atribuições guerreiras.Coma modernização dosexércitos ea abertura de espaço para aqueles que não vinham das grandes casas, os critérios para o recebimento de distinções foram alterados, tornando possível desvincular serviço militar e nobreza de nascimento. Isso ganhou cada vez maior vulto durante o longo processo de profissionalização das armas.

A honra militar estava relacionada à interiorização de padrões de conduta que incluíam a retidão do comportamento, ocumprimento das normas eas devidas demonstrações de bravura. Os debates sobre a motivação para o serviçomilitarocorridosnasegunda metadedosetecentosem Portugaleem outros países europeus conduziram à ideia de que a honra seria um fator de motivaçãomuitoeficaz. Elalevaria os soldadosaatuaçõesconstantes, consequentes, e garantiria uma melhor interiorização da disciplina, aspecto muito mais importante para os novos exércitos do que a obediência cega, e sem iniciativa, que antes se obtinha pelo medo. O reforço da hierarquia, a exigência de que as promoções se dessem de modo gradual, a aplicação de exames e a revalorização das ordens militares foram medidas tomadas pela Coroa portuguesa para dar visibilidade aos"... sinais de honra que expressam uma trajetória social ascendente" ${ }^{\prime 43}$ nos quadros militares do reino de Portugal.

Raimundo justificou sua participação na guerra como consequência de sua busca pessoal de reconhecimento e de honra. ORegimento de Artilharia

${ }^{43}$ COSTA, Fernando Dores. Op. Cit, 1998, p. 988. Ver também LYNN, John A. “Forum: Toward an Army of Honor: the moral evolution of the French Army, 1789-1815". Em: French Historical Studies, Durham, Vol. 16, No. 1. (Spring, 1989), p. 153. Disponível em: http://links.jstor.org/ sici?sici=0016-1071\%28198921\%2916\%3A1\%3C152\%3ATAAOHT\%3E2.0.CO\%3B2-E. 
destinado à campanha, segundo ele, fora organizado pela agregação de duas companhias de soldados voluntários enviadas por cada um dos quatro regimentos de artilharia do reino. Tal dinâmica divergiu da empregada pelas demais armas participantes da campanha, cujos contingentes formaram-se peloenviodealgunsregimentospré-existentesemPortugalequeviriamaser completados por homens de diferentes praças. ${ }^{44}$

Ele interpretou o modo peculiar de formação da artilharia como decorrente das expectativas da Coroa em fazer boa figura ante os espanhóis: "... o governo pretendia apresentar em Companhia a flor da Artilharia Portuguesa, um corpo que rivalizasse em instrução, e todo outro merecimento, com os brilhantes e científicos oficiais da Artilharia Espanhola." Na reconstrução elaborada por Raimundo José da Guerra do Rossilhão, essas tropas portuguesas atuaram de modo exemplar e foram merecedoras de menções honrosas por parte dos oficiais.

Devemos observar, aliás, que o comando da artilharia da Divisão Auxiliadora à Coroa de Espanha recebeu os maiores elogios, tanto nas Memórias quanto nos relatórios e comentários da época. O Marechal de Campo Francisco Xavier de Noronha e os majores José António da Rosa e António Teixeira Rebelo eram oficiais de origem modesta, que assentaram praça no contexto da Guerra Fantástica, ealcançaram o oficialato ao serem aprovados naschamadasoposições, ouseja, provasexigidasaoscandidatosà promoção aos postos militares.

A Divisão Auxiliadora foi retratada, podemos concluir ao final da leitura do documento, como um contraponto moderno, herdeiro da ação de Lippe, diante do Exército Espanhol, marcado por práticas do Antigo Regime, a despeito das qualidades dealguns dos seussetores. Fora,justamente, odescompasso entre as'luzes do século'e os vícios aristocráticos do Exército espanhol a causa principal, segundo Cunha Mattos, para a derrota das tropas ibéricas.

A experiência no teatro da guerra foi apresentada por Raimundo José como o ápice de sua formação. A partir de então, ele percebeu e se afirmou como um militar. Como tal ele atuou ao longo de sua trajetória e nos diferen-

${ }^{44}$ MATTOS, Raimundo José da Cunha. Memórias. 
tes espaços nos quais circularia nos últimos anos do Império luso-brasileiro e nos primeiros do Império do Brasil. É possível afirmar que Raimundo José secompreendia como partícipe decerta experiência militarinfluenciadapor esforçosdesuperaçãodasmarcasaristocráticas de Exércitoequeexperimentou os benefícios e as frustrações decorrentes da parcialidade das reformas militares.

\section{Considerações finais}

Retomemosoiníciodesteartigoeascolocaçõesarespeitodaintencionalidadedostextosautobiográficos. RaimundoJosédaCunhaMattos retratousecomo um militaroriundodefamíliasimples, constituída porsoldados, eesforçou-se em desvincular sua ascensão profissional e social da"economia de favores"quemarcavao Antigo Regime.$^{45} \mathrm{Aleiturade}$ diferentestextosproduzidosporelemostraqueafixaçãodessaimagemdesimesmafoiperseguidaao longo de sua vida. A iniciativa de escrever suas memórias, em diálogo com as normasdodiscursohistoriográficodeentão,foiumdosmomentosmaisexplícitosdaqueleesforço. ${ }^{46}$ Garantiraveracidadedesuanarrativaeraelementoimportanteparaosucessonaconstruçãodesuareputaçãopessoaleprofissional.

Em suas Memórias, no intento de dar sentido a sua própria trajetória, Raimundo José deparou-se com a complexidade do momento histórico em que vivia, quando acontecimentos políticos e sociais exigiram de seus contemporâneosadesões políticas, reconstruçõesidentitárias edeslocamentos geográficosque,necessariamente,conduziramaavaliaçõesereavaliaçõesde experiências, desejos e projetos.

Foram décadas marcadas pelas revoluções que, desde o último quartel do século XVIII, fortaleceram a percepção de que se vivia um tempo novo:

${ }^{45}$ HESPANHA, António Manuel e XAVIER, Ângela Barreto. "As redes clientelares". In: HESPANHA, António Manuel (org.) História de Portugal, vol. IV - O Antigo Regime (1620-1807). Editorial Estampa: Lisboa, 1998, p. 339-349.

${ }^{46}$ Sobre sua trajetória, ver: RODRIGUES, Neuma Brilhante. Nos caminhos do Império: a trajetória de Raimundo José da Cunha Mattos. 2008. Tese (Doutorado em História) - Departamento de História, Universidade de Brasília, Brasília, 2008. 
a modernidade. ${ }^{47}$ No Brasil, especificamente, a experiência do contexto da independência conduziuà reconfiguração de expectativas que envolviamo jovem país, o que, por sua vez, levou à ressignificação do passado, numa relaçãodinâmicaereflexivaque,registradanaquelepresente,ligavaopassadoda monarquia portuguesa ao futuro do império brasileiro. ${ }^{48}$ "Os tempos têm alterado os costumes, ou os costumes têm alterado os tempos".49 Assim Cunha Mattos registrouem suas Memórias, em tom reflexivo, a sensação deviverem meio a mudanças e, como algumas passagens de seu escrito mostram, nem sempre positivas.

A situação das armas no país no momento da escrita das Memórias obviamente desagradava o então Brigadeiro do Exército Brasileiro e membro da Câmara dos Deputados. ${ }^{50}$ Em algumas passagens do texto, encontramos críticas às condições dos arsenais, ao despreparo das tropase, principalmente, ao desmerecimento de promoções de oficiais e ocupação de postos de comando,inclusivenocontextodeguerras, porpessoasdespreparadas,cujos principais atributos eram a proximidade com os grandes. No contexto da Cisplatina, provável panodefundodasMemórias, a críticacaía perfeitamente sobre a escolha do Marquês de Barbacena, notório amigo do Imperador, como comandante em chefe das tropas.

Nesse sentido, a ressignifação da Guerra do Rossilhão empreendida por Raimundo José pode ser lida como uma avaliação das estratégias seguidas por ele e seus antecedentes diretos como personagens de uma história do confronto entre dois tipos distintos de exército: um aristocrático e outro moderno. Em sua narrativa, as tropas espanholas envolvidas no conflito servi-

${ }^{47}$ KOSELLECK, Reinhart. The Practice of Conceptual History, Stanford University Press:Stanford, 2002.

${ }^{48}$ Aressignificaçãodo período colonial nos debates nocontexto da independênciae os seus desdobramentosnarepresentaçãodaqueleperíodopelahistoriografiabrasileiraforamanalisados,entreoutros, por Tereza Cristina Kirschnner no artigo “Um pouco de historiografia: a representação do passado colonial brasileiroa partirda independência”, Anais deHistória de Além-mar,vol.X,2009, pp.249-275.

49 MATTOS, Raimundo José da Cunha. Memórias.

50 O manuscrito não está datado, mas referências a personagens e contextos permitem supor que foi elaborado entre os últimos anos da década de 1820 e os primeiros da seguinte. Cunha Mattos comentou, por exemplo, acerca das nobilitações de Francisco de Paula Leite de Sousa e de Manuel Inácio Corte Real, ambas ocorridas em 1823, em Portugal. Por outro lado, não tinha ainda conhecimento da morte daquele último, ocorrida em outubro de 1832. 
riamcomoexemplodos vícioseperigos decorrentes da concepçãoaristocrática de Exército, enquanto a Divisão Auxiliadora - especialmente a artilharia - seria retratada como uma'tropa ideal'imbuída de valores modernos e com aspirações profissionalizantes, fruto das reformas de Lippe, interpretadas a partir de um espaço de experiência pós-napoleônico.

Tal representação não significava, contudo, que Raimundo José considerava que as reformas foram completamente bem sucedidas. A Artilharia e a Divisão Auxiliadora, corpos aos quais pertenceu o memorialista, foram apresentadas como excepcionalidades que destoavam entre outros corpos militares do mundo luso-brasileiro e brasileiro. Mesmo a Artilharia não teria cumprido em plenitude sua vocação meritocrática, como retratam as carreiras de Francisco Xavier e Alexandre Manoel. No caso do primeiro, morreu dependente da caridade de terceiros e, no do segundo, preterido de promoçõesa despeito das décadas debonsserviços prestados.OpróprioRaimundo José, a despeito dopostodegeneralatoalcançado, seviu, naCisplatina,como vítima dainvejadesuperiores despreparadosque, nafaltadalegitimidadede suas indicações, comandavam pela força.

As trajetórias dos Cunha Mattos aqui traçadas, em suas particularidades enão como representativas de determinado grupo, permitem percebermeIhor a complexidade do tecido social. As carreiras dos três sujeitos históricos em questão foram marcadas pelas expectativas, frustrações, negociações e adaptações impostas por seus contextos.

\section{Fontes}

Alvará de 19 de junho de 1789. Disponível em http://www.iuslusitaniae. fcsh.unl.pt/verlivro.php?id_parte=109\&id_obra=73\&pagina $=817$.

ANDRADE,GomesFreirede.EnsaiosobreométhododeorganizaremPortugalo Exércitorelativoàpopulação,agriculturaedefesadopaís.NovaOfficinadeJoão Rodrigues Neves: Lisboa, 1806, p. V.

ANTT, Conselho de Guerra - Decretos. Decreto de 20 de julho de 1763 e Decreto n. 138 de 1 de setembro de 1764.

ANTT, Decretos do Ministério do Reino, maço 60, ano 1798, processo 420. 
CondedeLippe.PlanodeArtilharia.Disponívelem:http://www.iuslusitaniae. fcsh.unl.pt/verlivro.php?id_parte=108\&id_obra=73\&pagina $=45$, acessado em 27/12/2015.

CUNHA MATTOS. AHU_CU_070_CX 38 , D 1. Certidão datada de 20 de maio de 1811.

Conde de Lippe. "Plano que Sua Majestade manda seguir e observar no estabelecimento, estudos exercícios das aulas dos Regimentos de ArtiIharia,de15dejulhode1763".In:Collecçãodalegislaçãoportuguezadesdea ultimacompilaçãodasordenações,redigidapeloDesembargadorAntónioDelgadoda Silva. Legislação de 1763 a 1774. Lisboa: Typographia Maigrense, 1829.

CondedeLippe.Regulamentoparaoexercícioedisciplinadosregimentosdeinfantaria dosexércitosdeSuaMajestadeFidelíssima.SecretariadeEstado:Lisboa,1763.

CondedeLippe.Memóriasobreosexercíciosdemeditaçãomilitarparaseremeteraos senhoresGeneraiseGovernadoresdeProvíncias.Lisboa:OficinadeJoãoAntónio da Silva, 1782.

MATTOS, Raimundo José da Cunha. Memórias políticas, militares e biográficas. Biblioteca Nacional do Rio de Janeiro (BNRJ), Seção de Manuscritos, 10,2,016.

Portugal (AHMP), Lisboa, AHMP/DIV/3/7 - Mattos, Raimundo José da Cunha.

Requerimento do Brigadeiro Christianno Frederico de Weinholtz, 1786. AHMP, Lisboa, 3/5/2/24.

SILVA, José Bonifácio de Andrada e Silva. Elogio acadêmico da Senhora d. Maria Primeira, recitado por José Bonifácio de Andrada e Silva em sessão pública da Academia Real das Sciências de Lisboa, aos 20 de março de 1817. Typographia Imparcial de Francisco de Paula Brito: Rio de Janeiro, 1839.

\section{Bibliografia}

ALBERTI, Verena. "Literatura e autobiografia." In: Estudos Históricos. Rio de Janeiro, vol. 4, n. 7, 1991.

BEBIANO, Rui. "Os imaginários, os valores e os ideais da guerra." In: HESPANHA, António Manuel. Nova História militar de Portugal.Vol. Il.Círculo de Leitores: Lisboa, 2004, p. 36-62.

. A pena de marte: escrita da guerra em Portugal e na Europa (sécs. XVI- 
-XVIII). Minerva: Coimbra, 2000.

COSTA, Fernando Dores. "O bom uso das paixões: caminhos militares na mudança do modo de governar." In: Análise Social. Lisboa, vol. XXXIII (149), $1998\left(5^{\circ}\right)$.

GUSDORF, Georges. “De l'autobiographie initiatique à l'autobiographie genrelittéraire."In:Revued'HistoireLittérairedelaFrance.Paris,75eAnnée, n. 6, Nov-Dec, 1975.

. "Fidalgos e Plebeus" e "Guerra no tempo de Lippe e de Pombal". In: HESPANHA, António Manuel. Nova História militar de Portugal.Vol.II. Círculo de Leitores: Lisboa, 2004.

HESPANHA, António Manuel e XAVIER, Ângela Barreto. "As redes clientelares". In: (org.) História de Portugal, vol. IV - O Antigo Regime (1620-1807). Editorial Estampa: Lisboa, 1998, pp. 339-349.

KODAMA, Kaori. Itinerários, corografias e escritas da história: as viagens e os registros de Raimundo José da Cunha Matos no Império do Brasil. Escritos. Revista da Fundação Casa de Rui Barbosa. Rio de Janeiro, Ano 2, n. 2, 2008, p. 373-395.

KOSELLECK, Reinhart. The Practice of Conceptual History, Stanford University Press: Stanford, 2002.

LAQUEUR,Walter.Thursday's Child HasFar to Go:AMemoir of the Journeying Years. New York: Scribner, 1993.

LEVI, Giovanni. Usos da biografia. In: FERREIRA, Marieta de Moraes; AMADO, Janaína. Usos e abusos da história oral. 8a.ed. Rio de Janeiro: Ed. FGV, 2006.

LOPES,JoãoBaptistadaSilva.Corografiaoumemóriaeconômica,estatísticaetopográficadoReinodoAlgarve.AcademiadasCiênciasdeLisboa:Lisboa, 1841.

LYNN, John A. "Forum: Toward an Army of Honor: the moral evolution of the French Army, 1789-1815". In: French Historical Studies, Durham, Vol. 16, No. 1. (Spring, 1989). Disponível em: http://links.jstor.org/sici?sici=0016-1071\%28198921\%2916\%3A1\%3C152\%3ATAAOHT\%3E2.0. CO\%3B2-E.

MARTINS,CarlosHenrique.OprogramadeobraspúblicasparaoPortugalcontinental, 1789-1809. Vol. II. Tese de Doutoramento em Arquitetura, Universidade de Coimbra, 2014. Disponível em: https://estudogeral.sib. uc.pt/handle/10316/25713 
MONTEIRO, Nuno Gonçalo. Elites locais e mobilidade social em Portugal nos finais do Antigo Regime. In: Análise Social. Lisboa, volume XXXII (141), p. 335-3681997 (2º.

"Comandos militares e elites sociais." In: HESPANHA, António Manuel. Nova História militar de Portugal.Vol. Il. Círculo de Leitores: Lisboa, 2004, p. 103-105.

QUEIRÓ,JoãoFilipe.JoséAnastáciodaCunha:ummatemáticoarecordar,200 anosdepois.In:BoletimdaSociedadePortuguesadeMatemática,n²9,setembrode 1994, p. 2. Disponível em: http://www.mat.uc.pt/ jfqueiro/cunha.pdf.

RODRIGUES, Neuma Brilhante. "Para a utilidade do estado e "glória à nação": a real casa pia de Lisboa nos tempos de Pina Manique (17801805)". In: Revista Territórios e Fronteiras v.1, n.2, Jul/Dez, 2008, p. 23-41, 2008. Disponível em: http://www.ppghis.com/territorios\&fronteiras/ index.php/v03n02/article/view/15.

SOUZA, Adriana Barreto de. Pesquisa, escolha biográfica e escrita da história: biografando o duque de Caxias. História da Historiografia Ouro Preto, n. 9, , ago. 2012, p. 106-128.

Recebido: 15/06/2016 - Aprovado: 26/06/2017 